\title{
Polytetrafluoroethylene bridge for atrioventricular valve repair in single-ventricle palliation
}

\author{
Koichi Sughimoto, MD, PhD, ${ }^{\mathrm{a}}$ Igor E. Konstantinov, $\mathrm{MD}, \mathrm{PhD},{ }^{\mathrm{a}, \mathrm{b}, \mathrm{c}}$ Christian P. Brizard, MD, ${ }^{\mathrm{a}, \mathrm{b}, \mathrm{c}}$ and \\ Yves d'Udekem, MD, PhD, ${ }^{\mathrm{a}, \mathrm{b}, \mathrm{c}}$ Melbourne, Australia
}

Common atrioventricular valve regurgitation has been identified as a predictor of adverse outcomes in patients with singleventricle physiology. ${ }^{1}$ The observed worse prognosis of patients who have common atrioventricular valve has been attributed to the propensity of these valves to become regurgitant. We recently reported that up to $50 \%$ of the patients with single-ventricle physiology and common atrioventricular valve requiring valve surgery would die within 5 years of their valve surgery. ${ }^{2}$ The predominant techniques described to repair common atrioventricular valves are the edge-to-edge repairs or annuloplasty, ${ }^{3}$ which we found give unreliable results. ${ }^{2}$ Here, we describe a derivation of this technique that consists of the apposition of the central portion of the leaflets and stabilization with an annulus-to-annulus polytetrafluoroethylene (PTFE) bridge (this bridge is Gore-Tex, a registered trademark of W.L. Gore \& Associates, Inc., Flagstaff, Ariz).

\section{METHODS}

Four patients, age 4 months, 1.9 years, 2.4 years, and 4.7 years, respectively, underwent a repair of common atrioventricular valve, including stabilization of the central portion of the valve with the PTFE (Gore Tex) bridge at the time of a bidirectional cavopulmonary shunt (BCPS) procedure (1), Fontan completion (1), or apart from either procedure (2). They suffered from moderate (3) or severe (1) atrioventricular valve regurgitation. All patients had right atrial isomerism and unbalanced atrioventricular septal defect, and 2 had dextrocardia. All patients displayed multiple jets of central regurgitation.

The repair was initiated by close inspection of the valve with multiple injections of saline in the ventricle. A kissing point between the superior and inferior bridging leaflets in their middle portion was identified and secured with separate 6-0 polypropylene sutures (Prolene, Ethicon, Somerville, NJ). The zone of apposition between the superior and inferior bridging leaflets of

From the Department of Cardiac Surgery, ${ }^{\text {a }}$ The Royal Children's Hospital, Melbourne; Murdoch Children's Research Institute, ${ }^{\mathrm{b}}$ Melbourne; and Department of Paediatrics, ${ }^{c}$ Faculty of Medicine, The University of Melbourne, Melbourne, Australia.

This work was supported by the Victorian Government's Operational Infrastructure Support Program

Disclosures: Yves d'Udekem is a Career Development Fellow of The National Heart Foundation of Australia Research Program (CR 10M 5339). Christian P. Brizard reports consulting fees from Admedus Australia. All other authors have nothing to disclose with regard to commercial support.

Received for publication July 23, 2014; revisions received Oct 7, 2014; accepted for publication Oct 18, 2014; available ahead of print Nov 14, 2014.

Address for reprints: Yves d'Udekem, MD, PhD, Department of Cardiac Surgery, Royal Children's Hospital, Flemington Rd, Parkville, Melbourne, Victoria 3052,

Australia (E-mail: yves.dudekem@rch.org.au).

J Thorac Cardiovasc Surg 2015;149:641-3

$0022-5223 / \$ 36.00$

Copyright $\odot 2015$ by The American Association for Thoracic Surgery

http://dx.doi.org/10.1016/j.jtcvs.2014.09.126 the right and left side of the atrioventricular valve were closed with additional separate sutures, including some pseudo-commissures. Finally, a 0.4-mm PTFE (Gore Tex) patch was trimmed and secured to the anterior and posterior valve annulus with CV-6 PTFE (Gore-Tex) sutures. The PTFE strip was secured to the leaflet with several separate polypropylene (Prolene) sutures (Figure 1). No additional annuloplasty was performed.

\section{RESULTS}

The immediate postoperative transesophageal echocardiographic examinations showed no more than mild regurgitation in 3 patients, and mild to moderate regurgitation in one. In this latter patient, the regurgitation was attributed to a central leak in the hypoplastic right side of the valve, which we opted not to treat at that stage, to avoid annuloplasty. After a median of 21 months (range: 14-68 months), all patients were alive and described themselves as being in New York Heart Association class I. One patient completed the Fontan procedure, 2 additional patients are awaiting Fontan completion, and one is waiting for a BCPS procedure. At the last follow-up, 3 patients had mild or trivial atrioventricular valve regurgitation, whereas the mild to moderate regurgitation of the last patient seemed unchanged.

\section{CONCLUSIONS}

It is likely that the adverse outcomes identified in patients with common atrioventricular valve, who receive treatment via a single ventricular palliation pathway, are due to the natural propensity of these valves to become regurgitant. We have not found annuloplasty and edge-to-edge repairs to provide lasting results in these very young and therefore small patients, and tried to explore other techniques. ${ }^{2} \mathrm{We}$ believed that achieving competence of these common atrioventricular valves would require stabilization of their central portion in a similar way to that in a biventricular repair. Takayama and colleagues ${ }^{4}$ had already suggested suturing Teflon tape to the central portion of the leaflets to achieve valvular functioning, associated with a circumferential annuloplasty; we applied a PTFE (Gore-Tex) bridge exclusively to stabilize the facing leaflets. This PTFE (Gore Tex) material has been recognized to promote native tissue ingrowth, ${ }^{5}$ and in a patient who underwent reoperation for augmentation of the pulmonary venous return 1 year after the repair, we confirmed that this patch material was embedded into the underlying valvular tissue (Figure 2).

We found that although the edge-to-edge repair acquires the apposition between the superior and inferior bridging 

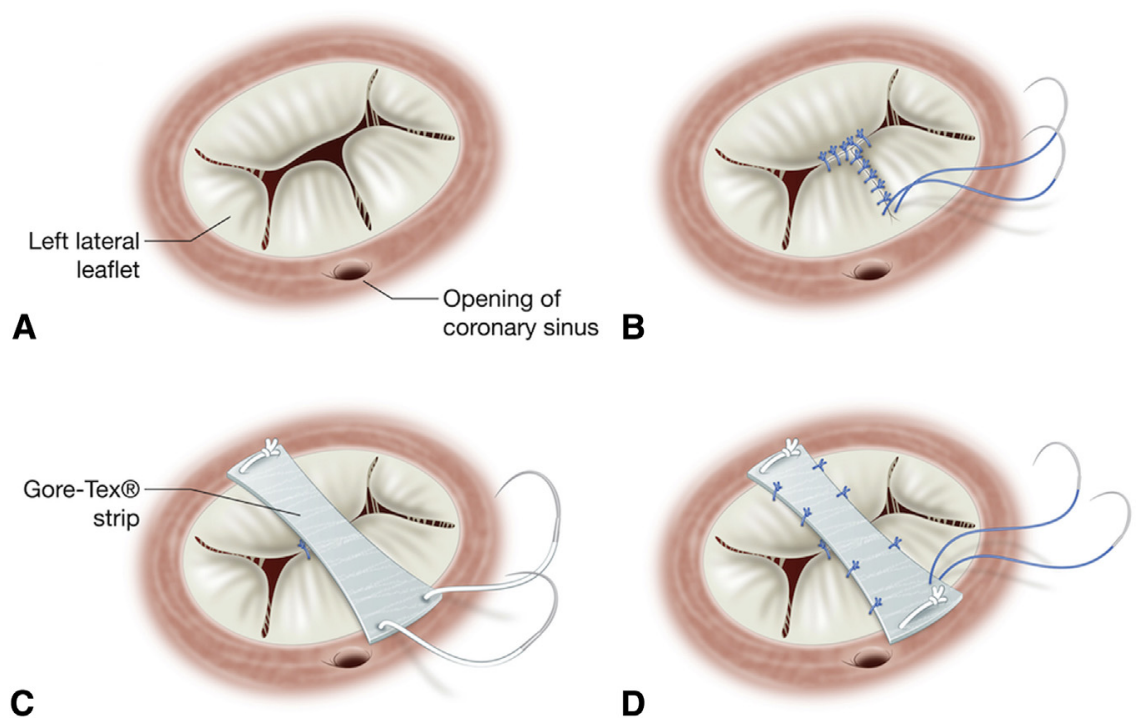

FIGURE 1. A, Common atrioventricular valve anatomy, surgical view. B, The superior and inferior bridging leaflets are approximated with Prolene (Ethicon, Somerville, NJ) (polypropylene) sutures, whereas the cleft between the left component of the superior and inferior bridging leaflets is closed with Prolene sutures. C, A PTFE strip (this is a Gore-Tex strip, a registered trademark of W.L. Gore \& Associates, Inc., Flagstaff, Ariz) is trimmed and sutured to the annulus with PTFE (Gore-Tex) sutures. D, The strip is secured to the leaflets with several polypropylene (Prolene) sutures.

leaflets on a single focal point, this pledget-reinforced suture is often bulky. The current technique allows the approximation of larger areas of zone of apposition between leaflets, leaving the potential for annular growth. In addition, it allows the closure of some pseudo-commissures, or the cleft between the left component of the superior and inferior bridging leaflets, allowing a much more refined and targeted closure of all the culprit lesions.

We are now offering atrioventricular repair at the same time as the BCPS procedure, or as a separate procedure before the Fontan procedure. We believe that a separate procedure before Fontan completion is justified because the patients will be in better condition to go through the Fontan surgery. Performing a repair as a separate procedure before Fontan completion also gives us an additional possibility to work on the valve at the time of the Fontan surgery to improve suboptimal repairs. As an example, the patient now left with moderate regurgitation will undergo a further closure of this portion of the valve in the planned Fontan completion. Obviously, longer

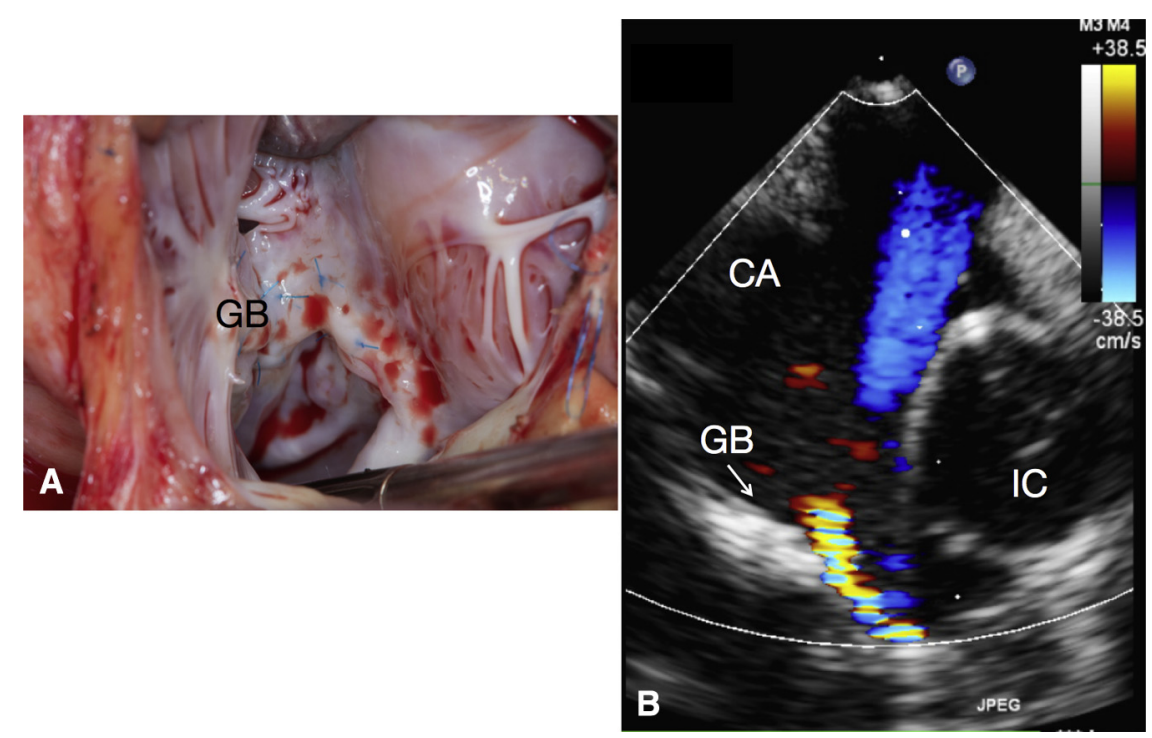

FIGURE 2. Imaging of the PTFE bridge (this bridge is Gore-Tex, a registered trademark of W.L. Gore \& Associates, Inc., Flagstaff, Ariz) during a reoperation of the Fontan circuit 1 year after repair. A, Intraoperative view of the embedded PTFE (Gore-Tex) bridge, 1 year after repair. B, Intraoperative transesophageal echocardiography showing only mild atrioventricular valve regurgitation. $G B$, Gore-Tex bridge; $C A$, common atrium; $I C$, intracardiac conduit. 
follow-up is necessary to ascertain the long-term effectiveness of this technique.

\section{References}

1. d'Udekem Y, Iyengar AJ, Cochrane AD, Grigg LE, Ramsay JM, Wheaton GR, et al. The Fontan procedure: contemporary techniques have improved long-term outcomes. Circulation. 2007;116(11 Suppl):I157-64.

2. Wong DJ, Iyengar AJ, Wheaton GR, Ramsay JM, Grigg LE, Horton S, et al. Long-term outcomes after atrioventricular valve operations in patients undergoing single-ventricle palliation. Ann Thorac Surg. 2012; 94:606-13.

3. Ando M, Takahashi Y. Edge-to-edge repair of common atrio-ventricular or tricuspid valve in patients with functionally single ventricle. Ann Thorac Surg. 2007;84:1571-6.

4. Takayama T, Nagata N, Miyairi T, Abe M, Koseni K, Yoshimura Y. Bridging annuloplasty for common atrioventricular valve regurgitation. Ann Thorac Surg. 1995;59:1003-5.

5. Bortolotti U, Milano AD, Frater RW. Mitral valve repair with artificial chordae: a review of its history, technical details, long-term results, and pathology. Ann Thorac Surg. 2012;93:684-91. 